\title{
Advances in the management of esophageal cancer
}

Bruce D. MINSKY

\begin{abstract}
The management of clinical stage III and IVa esophageal cancer has evolved in the past 2 decades. Based on the Cross trial, neoadjuvant chemoradiation, followed by surgical resection has become standard. For medically inoperable, definitive chemoradiation is most commonly used. The standard radiation dose is 50.4 Gy although trials of doseescalation are ongoing. At the current time, there are no definitive biomarkers to predict response.
\end{abstract}

Keywords: Esophageal cancer, Radiation therapy, Chemotherapy, Dose-escalation

\section{NONOPERATIVE THERAPY}

\section{Radiation therapy alone}

Radiation therapy alone is limited to palliation or for patients who are medically unable to tolerate chemotherapy. The 5-year survival rate for patients treated with conventional doses of radiation therapy alone is $0-10 \%$ [1-3]. In the radiation therapy alone arm of the RTOG 85-01 trial in which patients received 64 Gy at $2 \mathrm{~Gy} /$ day with conventional techniques, all patients were all dead of disease by 3 years [4,5]. Shi and

Bruce D. Minsky, M.D., (区)

Department of Radiation Oncology,

The University of Texas MD Anderson Cancer Center,

Houston, Texas, 77030

email:bminsky@mdanderson.org colleagues reported a 33\% 5-year survival rate with the use of late course accelerated fractionation to a total dose of 68.4 Gy [6-12].

\section{Dose intensification with brachytherapy}

Brachytherapy can be delivered by low or high dose rates and has previously been used as a boost following external beam radiation therapy or chemoradiation [7-16]. This technique is limited by the effective treatment distance. The primary isotope is 192Ir, which is usually prescribed to treat to a distance of $1 \mathrm{~cm}$ from the source. Therefore, as confirmed by pathologic analysis of treated specimens, any portion of the tumor which is $>1 \mathrm{~cm}$ from the source will receive a suboptimal radiation dose [17].

Retrospective and single institution trials suggest that there is no advantage of adding brachytherapy to external beam radiation. Chemoradiation plus brachytherapy was tested prospectively by the RTOG 92-07 trial. A total of 75 patients with cancers of the thoracic esophagus $(92 \%$ squamous cell, 8\% adenocarcinoma) received the RTOG 85-01 50 Gy chemoradiation regimen followed by a boost during cycle 3 of chemotherapy with either low dose rate or high dose rate intraluminal brachytherapy [22]. Due to low accrual the low dose rate option was discontinued and the analysis was limited to patients who received the high dose rate treatment. High dose rate brachytherapy was delivered in weekly fractions of 5 Gy during weeks 8, 9, and 10. Several patients developed fistulas and the fraction delivered at week 10 was discontinued. The complete response rate was $73 \%$. With a median follow-up of only 11 months, local failure as the first site of failure was $27 \%$. Acute toxicities were high. These included 58\% grade 3, $26 \%$ grade 4 , and $8 \%$ grade 5 (treatment-related death). The 
cumulative incidence of fistula was $18 \%$ /year and the crude incidence was $14 \%$. Of the 6 treatment related fistulas, 3 were fatal. Given the significant toxicity and lack of efficacy there is limited interest in this technique.

However, if brachytherapy is to be used, guidelines for esophageal brachytherapy have been published by the American Brachytherapy Society are available [23]. For patients treated in the curative setting brachytherapy should be limited to tumors $\leq 10 \mathrm{~cm}$ with no evidence of distant metastasis. Contraindications include tracheal or bronchial involvement, cervical esophagus location, or stenosis which cannot be bypassed. The applicator should have an external diameter of $6-10 \mathrm{~cm}$. If chemoradiation is used (defined as 5-FU based chemotherapy plus 45-50 Gy) the recommended doses of brachytherapy are 10 Gy in 2 weekly fractions of 5 Gy each for high dose rate and 20 Gy in a single fraction at 4-10 Gy/hr for low dose rate. The doses should be prescribed to $1 \mathrm{~cm}$ from the source. Lastly, brachytherapy should be delivered after the completion of external beam and not concurrently with chemotherapy.

\section{Primary chemoradiation}

Although there are 6 randomized trials comparing definitive radiation therapy alone with chemoradiation, the only trial which designed to deliver adequate doses of systemic chemotherapy with concurrent radiation therapy was the RTOG 85-01 trial reported by Herskovic and colleagues [2326]. As was common in the 1980s, most patients had SCC. Treatment included four cycles of 5 -FU $(1000 \mathrm{mg} / \mathrm{m} 2 / 24$ hr x 4 days) and Cisplatin ( $75 \mathrm{mg} / \mathrm{m} 2$, day 1). Radiation therapy (50 Gy at 2 Gy/day) was given concurrently with the first day of cycle 1 of chemotherapy. Cycles 3 and 4 of chemotherapy were delivered every 3 weeks rather than every 4 weeks. Only $50 \%$ of the patients finished all 4 cycles of the chemotherapy. The control arm was radiation therapy alone, albeit a higher dose (64 Gy) than the chemoradiation arm.

Patients treated with chemoradiation had a significant improvement in both median (14 months vs. 9 months), and 5 year survival $(27 \%$ vs. $0 \%, \mathrm{p}<0.0001)$ [25]. The 8 year survival was $22 \%$ [26]. Histology did not significantly influence the results. The 5 -year survival was $21 \%$ for the 107 patients with SCC vs. $13 \%$ of the 23 patients with adenocarcinoma, $(\mathrm{p}=\mathrm{NS})$. Local failure (defined as local persistence plus recurrence) was also lower in the chemoradiation arm (47\% vs. 65\%). Although African Americans had larger primary tumors of which all were SCC, there was no difference in survival compared with Caucasians [27].

\section{Dose intensification with external beam escalation}

This concept was prospectively examined in INT 0123 (RTOG 9405) [29]. In this trial, patients selected for a nonsurgical approach were randomized to a slightly modified RTOG 85-01 chemoradiation regimen with 50.4 Gy versus the same chemotherapy with $64.8 \mathrm{~Gy}$, based on INT 0122 . As with RTOG $85-01$, the majority of patients $(85 \%)$ had SCC. The trial opened in late 1994 and was closed in 1999 when an interim analysis revealed that it was unlikely that the high dose arm would achieve a superior survival compared to the standard dose arm.

For the 218 eligible patients, there was no significant difference in median survival (13.0 months vs. 18.1 months), 2-year survival ( $31 \%$ vs. $40 \%)$, or local/regional failure and/or local/regional persistence of disease ( $56 \%$ vs. $52 \%$ ) between the high dose and standard dose arms. Although 11 treatment-related deaths occurred in the high dose arm compared with two in the standard dose arm, seven of the 11 occurred in patients who had received $\leq 50.4 \mathrm{~Gy}$.

An alternative approach to dose escalation is altered fractionation. This has revealed mixed results. Zaho and colleagues treated 201 patients with squamous cell cancer using 41.4 Gy followed by late-course accelerated hyperfractionation to $68.4 \mathrm{~Gy}$ [30]. The results were similar to RTOG 85-01 (38\% local failure and 26\% 5-year survival). Choi and colleagues treated 46 patients with 5-FU/cisplatin and BID radiation using a concurrent boost technique and reported a 37\% 5-year survival [31]. Additionally, Lee et al reported on a trial of 102 patients with LAEC, limited to SCC, randomized to surgery alone versus preoperative therapy with 45.6 Gy (1.2 Gy BID) plus 5-FU/cisplatin [32]. There was no difference in median survival (28 vs. 27 months). Thus, although these approaches may appear to be reasonable, there appears to be a significant increase in acute toxicity without any clear therapeutic benefit.

The above trials used 2D and 3D techniques. Newer techniques such as IMRT and protons may be able to deliver higher doses of radiation with a more tolerable toxicity profile. Multiple dosimetric studies comparing standard 3D-conformal radiotherapy and IMRT, generally have found improved sparing of the heart, lung or both using either static field or arc-based IMRT [33-44]. Retrospective data do not suggest inferior outcome and may provide decreased toxicity vs. nonIMRT treatment techniques [45-47]. Investigators at the MD Anderson reported the results of 676 patients treated with either IMRT (263) or 3DCRT (413) [45]. On multivariate analysis, IMRT was associated with improved survival $(\mathrm{p}=0.004)$, but not cancer specific survival $(\mathrm{p}=0.86)$. The survival difference between 3DCRT and IMRT was thought to be due to a higher 
level of cardiac $(\mathrm{p}=0.05)$ and unexplained deaths $(\mathrm{p}=0.003)$ in the 3DCRT patients, suggesting that decreased cardiac dose may have a direct impact on patient outcome. A randomized trial is unlikely, therefore the available data may represent the best comparison.

Another theoretical advantage of IMRT is the possibility of dose escalation. With the use of IMRT, a simultaneous integrated boost (SIB) may be performed while maintaining commonly used lung and heart dosimetric constraints. Retrospective data from Zhang and colleagues suggest a positive correlation between radiation dose and locoregional control [48].

\section{Neoadjuvant chemotherapy}

A potential advantage of neoadjuvant chemotherapy is the early identification of those patients who may or may not respond to the chemotherapeutic regimen being delivered concurrently with chemoradiation. Data from Ilson et al suggest that the change in SUV on FDG-PET scan was able to predict which patients showed a response to chemotherapy [49]. Weider and associates reported similar findings in 38 patients with squamous cell cancers [50]. Although this approach is investigational, if the non-responders can be identified early, changing the chemotherapeutic regimen may be helpful. However, in the context of induction chemotherapy prior to definitive chemoradiation, the data do not support its routine use. For example, Ruhstaller and colleagues report the outcomes from a phase II trial using cisplatin/docetaxel followed by chemoradiation [51]. The median survival was 16 months, with $29 \%$ of patients surviving long term suggesting no benefit over chemoradiation alone.

\section{NEOADJUVANT THERAPY}

\section{Preoperative chemoradiation}

There are seven randomized trials comparing preoperative combined modality therapy with surgery alone in patients with clinically resectable disease, the most recent being the CROSS trial [32, 55-60].

The CROSS trial randomized 366 patients $(75 \%$ adenocarcinoma, $23 \%$ squamous cell) to receive either neoadjuvant chemoradiation with 41.4 Gy and carboplatin/ paclitaxel followed by surgical resection versus surgical resection alone [60]. In median survival was 49.4 vs. 24 months, $\mathrm{p}=0.003$, respectively. Improved survival was seen in both adenocarcinoma and SCC, although the magnitude was slightly greater in squamous cell. The $\mathrm{R} 0$ resection was $93 \%$ in the chemoradiation arm, compared to $69 \%$ in the surgery alone arm $(\mathrm{p}<0.001)$ and the pCR rate was $29 \%$. There was no significant difference in perioperative complications was seen between treatment arms.

Prior to the publication of the CROSS trial the role of preoperative chemoradiation was controversial. The first 6 trials (Urba [55], Walsh [56], EORTC [57], Australasian [58], Korea [32], and CALGB 9781 [59]) had limited patient numbers, heterogeneous treatment regimens, and in some the dose of radiation was insufficient based. With the publication of the CROSS trial the standard of care for patients with locally advanced but medically resectable adenocarcinoma of the esophagus is now preoperative chemoradiation.

\section{Is surgery necessary following chemoradiation?}

Given the response rate to chemoradiation and the morbidity of surgery, two randomized trials have examined whether surgery is necessary after chemoradiation. In the Federation Francaise de Cancerologie Digestive (FFCD) 9102 trial, 445 patients with clinically resectable T3-4N0-1M0 SCC or adenocarcinoma of the esophagus received initial chemoradiation [64]. Patients initially received 2 cycles of 5-FU, cisplatin, and concurrent radiation (either $46 \mathrm{~Gy}$ at 2 Gy/day or split course 15 Gy weeks 1 and 3). The 259 patients who had at least a partial response were then randomized to surgery versus additional chemoradiation which included 3 cycles of 5-FU, cisplatin, and concurrent radiation (either 20 Gy at $2 \mathrm{~Gy} /$ day or split course $15 \mathrm{~Gy}$ ). There was no significant difference in 2-year survival (34\% vs. $40 \%, \mathrm{p}=0.56)$ or median survival (18 months vs. 19 months) in patients who underwent surgery versus additional chemoradiation. These data suggest that for patients who initially respond to chemoradiation, they should complete chemoradiation rather than stop and undergo surgery. Using the Spitzer index, there was no difference in global quality of life however, a significantly greater decrease in quality of life was observed in the surgery arm during the postoperative period ( 7.52 vs. $8.45, \mathrm{p}<0.01$, respectively) [65]. A separate analysis revealed that compared with split course radiation, patients who received standard course radiation had improved 2-year local relapse free survival rates $(77 \%$ vs. $57 \%, \mathrm{p}=0.002)$ but no significant difference in overall survival (37\% vs. $31 \%$ ) [66].

The second trial, from the German Oesophageal Cancer Study Group, compared preoperative chemoradiation followed by surgery versus chemoradiation alone [67]. In this trial, 172 eligible patients $<70$ years old with uT34N0-1M0 SCC were randomized to preoperative therapy (3 cycles of 5-FU, leucovorin, etoposide, and cisplatin, 
followed by concurrent etoposide, cisplatin, plus $40 \mathrm{~Gy}$ ) followed by surgery versus chemoradiation alone (the same chemotherapy but the radiation dose was increased to 60-65 Gy +/- brachytherapy). The pCR rate was 33\%. Although there was a decrease in 2-year local failure (36\% vs. $58 \%$, $\mathrm{p}=0.003)$ there was no significant difference in 3-year survival ( $31 \%$ vs. $24 \%$ ) for those who were randomized to preoperative chemoradiation followed by surgery vs. chemoradiation alone.

Despite the above data, the current standard of care is to perform esophagectomy following chemoradiation in patients that can tolerate this approach. However, it is known that a subset of patients will have a complete response to chemoradiation. Further, it is known that patients with pCR have improved survival. Data from both Berger et al [68] and Rohatgi et al [69] suggest that patients who achieve a pCR had an improvement in survival compared to those who do not (5-year: $48 \%$ vs. $15 \%$, and median: 133 months vs. 34 months, respectively). In these patients, surgical resection may not be necessary and has led to the concept of "selective" surgery after preoperative chemoradiation. Swisher and colleagues reported a retrospective analysis of patients who underwent a salvage compared with a planned esophagectomy [70]. The operative mortality was higher in those who underwent salvage vs. planned surgery (15\% vs. $6 \%$ ) but there was no difference in survival (25\%).

However, only 13 patients were identified who had salvage, limiting the broad interpretation of these findings. However, a recent phase II trial, RTOG 0246, prospectively examined the approach of preoperative paclitaxel/CDDP and 50.4 Gy followed by selective surgery in patients with either residual disease or recurrent disease in the absence of distant metastasis. In this trial of 43 patients with LAEC, 21 patients required surgical resection after chemoradiation due to residual (17 patients) or recurrent (3 patients) disease [71]. This approach led to a one year overall survival of $71 \%$, lower than the predetermined survival rate $(77.5 \%)$. Since all patients do not undergo surgery after neoadjuvant therapy, the use of a definitive does of radiation (50.4 Gy) rather than $41.4 \mathrm{~Gy}$, is recommended.

\section{Conclusions}

The management of esophageal cancer continues to evolve. Approaches include both preoperative and non-operative approaches, based on resectability, histology and location. In patients with resectable disease, who are medically fit for this procedure, we recommend preoperative chemoradiation to $50.4 \mathrm{~Gy}$. One possible exception to this recommendation is SCC of the cervical esophagus, for which definitive chemoradiation should be considered. Additionally, in nonoperative patients, definitive chemoradiation to 50.4 Gy is standard; however enrollment of these patients on doseescalation or other protocols is encouraged. Future directions include evaluation of tumor biomarkers of response to chemoradiation with a goal of possibly omitting surgery in favorable patients, while targeting non-responders for protocol based chemotherapy and radiosensitizers.

\section{References}

1. De-Ren S. Ten-year follow-up of esophageal cancer treated by radical radiation therapy: analysis of 869 patients. Int J Radiat Oncol Biol Phys 1989;16:329-34. doi:10.1016/0360-3016(89)90324-6

2. Newaishy GA, Read GA, Duncan W, Kerr GR. Results of radical radiotherapy of squamous cell carcinoma of the esophagus. Clin Radiol 1982;33:347-52. doi:10.1016/S0009-9260(82)80288-2

3. Okawa T, Kita M, Tanaka M, Ikeda M. Results of radiotherapy for inoperable locally advanced esophageal cancer. Int J Radiat Oncol Biol Phys 1989;17:49-54. doi:10.1016/0360-3016(89)90369-6

4. Smyth E, Schoder H, Strong VE, Capanu M, Kelsen DP, Coit DG, et al. A prospective evaluation of the utility of 2-deoxy-2-18F Fluoro-D-Glucose Positron Emission Tomography and computed tomography in staging locally advanced gastric cancer. Cancer 2012;118:5481-8. doi: 10.1002/cncr.27550

5. Kozak KR, Moody JS. The survival impact of the Intergroup 0116 trial on patients with gastric cancer. Int J Radiat Oncol Biol Phys 2008;72:517-21. doi:10.1016/j. ijrobp.2007.12.029

6. Shi X, Yao W, Liu T. Late course accelerated fractionation in radiotherapy of esophageal carcinoma. Radiother Oncol 1999;51:21-6. doi:10.1016/S01678140(99)00017-1

7. Moni J, Armstrong JG, Minsky BD, Bains MS, Harrison LB. High dose rate intraluminal brachytherapy for carcinoma of the esophagus. Dis Esoph 1996;9:123-7.

8. Calais G, Dorval E, Louisot P, Bourlie P, Klein V, Chapet $\mathrm{S}$, et al. Radiotherapy with high dose rate brachytherapy boost and concomitant chemotherapy for stages IIB and III esophageal carcinoma: results of a pilot study. Int J Radiat Oncol Biol Phys 1997;38:769-75. doi:10.1016/ S0360-3016(97)00077-1

9. Schraube P, Fritz P, Wannenmacher MF. Combined endoluminal and external irradiation of inoperable 
oesophageal carcinoma. Radiother Oncol 1997;44:4551. doi:10.1016/S0167-8140(97)00083-2

10. Akagi Y, Hirokawa Y, Kagemoto M, Matsuura K, Ito A, Fujita K, et al. Optimum fractionation for high-doserate endoesophageal brachytherapy following external irradiation of early stage esophageal cancer. Int J Radiat Oncol Biol Phys 1999;43:525-30.

11. Okawa T, Dokiya T, Nishio M, Hishikawa $\mathrm{Y}$, Morita K. Multi-institutional randomized trial of external radiotherapy with and without intraluminal brachytherapy for esophageal cancer in Japan. Int $\mathrm{J}$ Radiat Oncol Biol Phys 1999;45:623-8. doi: 10.1016/ S0360-3016(99)00253-9

12. Caspers RJL, Zwinderman AH, Griffioen G, Welvaart K, Sewsingh EN, Davelaar J, et al. Combined external beam and low dose rate intraluminal radiotherapy in oesophageal cancer. Radiother Oncol 1993;27:7-12. doi:10.1016/0167-8140(93)90038-A

13. Sur M, Sur R, Cooper K, Levin V, Bizos D, Dubazana $\mathrm{N}$. Morphologic alterations in esophageal squamous cell carcinoma after preoperative high dose rate intraluminal brachytherapy. Cancer 1996;77:2200-5. doi : 10.1002/ (SICI) 1097-0142(19960601)77:11<2200::AIDCNCR3>3.0.CO;2-T

14. Gaspar LE, Qian C, Kocha WI, Coia LR, Herskovic A, Graham M. A phase I/II study of external beam radiation, brachytherapy, and concurrent chemotherapy in localized cancer of the esophagus (RTOG 9207): Preliminary toxicity report. Int J Radiat Oncol Biol Phys 1995;32:160. doi: http://dx.doi.org/10.1016/03603016(95)97702-3

15. Gaspar LE, Nag S, Herskovic A, Mantravadi R, Speiser B. American Brachytherapy Society (ABS) consensus guidelines for brachytherapy of esophageal cancer. Int J Radiat Oncol Biol Phys 1997;38:127-32. doi:10.1016/ S0360-3016(97)00231-9

16. Herskovic A, Martz LK, Al-Sarraf M, et al. Combined chemotherapy and radiotherapy compared with radiotherapy alone in patients with cancer of the esophagus. New Engl J Med 1992;326:1593-8. doi: 10.1056/NEJM199206113262403

17. Al-Sarraf M, Martz K, Herskovic A, et al. Progress report of combined chemoradiotherapy versus radiotherapy alone in patients with esophageal cancer: An intergroup study. J Clin Oncol 1997;15:277-84.

18. Cooper JS, Guo MD, Herskovic A, Macdonald JS, Martenson JA, Al-Sarraf M, et al. Chemoradiotherapy of locally advanced esophageal cancer. Long-term follow-up of a prospective randomized trial (RTOG 85-01). JAMA 1999;281:1623-7. doi:10.1001/ jama.281.17.1623

19. Minsky BD, Pajak T, Ginsberg RJ, Pisansky TM, Martenson JA, Komaki R, et al. INT 0123 (RTOG 9405) phase III trial of combined modality therapy for esophageal cancer: high dose (64.8 Gy) vs. standard dose (50.4 Gy) radiation therapy. J Clin Oncol 2002;20:1167-74. doi: 10.1200/JCO.20.5.1167

20. Zaho KL, Shi XH, Jiang GL, Wang Y. Late course accelerated hyperfractionated radiotherapy for localized esophageal carcinoma. Int J Radiat Oncol Biol Phys 2004;60:123-9. doi:10.1016/j.ijrobp.2004.02.058

21. Choi N, Park SD, Lynch T, et al. Twice-daily radiotherapy as concurrent boost technique during chemotherapy cycles in neoadjuvant chemoradiotherapy for resectable esophageal carcinoma: mature results of a phase II study. Int J Radiat Oncol Biol Phys 2004;60:111-22. doi: 10.1016/j.ijrobp.2004.03.031

22. Lee JL, Kim SB, Jung HY, et al. A single institutional phase III trial of preoperative chemotherapy with hyperfractionation radiotherapy plus surgery versus surgery alone for resectable esophageal squamous cell carcinoma. Ann Oncol 2004;15:947-54. doi: 10.1093/ annonc/mdh219

23. Wu VWC, Sham JST, Kwong DLW. Inverse planning in three-dimensional conformal and intensity-modulated radiotherapy of mid-thoracic oesophageal cancer. Br J Radiol 2004;77:568-72. doi : http://dx.doi.org/10.1259/ bjr/19972578

24. Woudstra E, Heijmen BJM, Storchi PRM. Automated selection of beam orientations and segmented intensitymodulated radiotherapy (IMRT) for treatment of oesophagus tumors. Radiother Oncol 2005;77:254-61. doi: http://dx.doi.org/10.1016/j.radonc.2005.06.028

25. Lin SH, Wang L, Myles B, Thall PF, Hofstetter WL, Swisher SG, et al. Propensity score-based comparison of long-term outcomes with 3-dimensional conformal radiotherapy vs intensity-modulated radiotherapy for esophageal cancer. Int. J. Radiat. Oncol. Biol. Phys. 2012;84:1078-85. doi: http://dx.doi.org/10.1016/j.ijrobp. 2012.02.015

26. Wang S-L, Liao Z, Liu H, et al. Intensity-modulated radiation therapy with concurrent chemotherapy for locally advanced cervical and upper thoracic esophageal cancer. World J. Gastroenterol 2006;12:5501-8. doi: 10.3748/wjg.v12.i34.5501

27. La TH, Minn AY, Su Z, et al. Multimodality treatment 
with intensity modulated radiation therapy for esophageal cancer. Dis Esophagus 2010;23:300-8. doi: 10.1111/j.1442-2050.2009.01004.x

28. Zhang Z, Liao Z, Jin J, et al. Dose response relationship in locoregional control for patients with stage II-III esophageal cancer treated with concurrent chemotherapy and radiotherapy. Int $\mathrm{J}$ Radiat Oncol Biol Phys 2005;61:656-64. doi: 10.1016/j.jirobp.2004.06.022

29. Ilson DH, Bains M, Rizk NP, et al. Phase II trial of preoperative cisplatin-irinotecan followed by concurrent cisplatin-irinotecan and radiotherapy: PET scan after induction therapy may identify early treatment failure. Proc ASCO 2006;24:184s

30. Wieder HA, Brucher BLDM, Zimmermann F, et al. Time course of tumor metabolic activity during chemoradiotherapy of esophageal squamous cell carcinoma and response to treatment. J Clin Oncol 2004;22:900-8. doi: 10.1200/JCO.2004.07.122

31. Ruhstaller $\mathrm{T}$, Templeton $\mathrm{A}$, Ribi $\mathrm{K}$, et al. Intense therapy in patients with locally advanced esophageal cancer beyond hope for surgical cure: a prospective, multicenter phase II trial of the Swiss Group for Clinical Cancer Research (SAKK 76/02). Onkologie 2010;33:222-8. doi: 10.1159/000305094

32. Urba SG, Orringer MB, Turrisi A, Iannettoni $\mathrm{M}$, Forastiere A, Strawderman M. Randomized trial of preoperative chemoradiation versus surgery alone in patients with locoregional esophageal carcinoma. J Clin Oncol 2001;19:305-13. doi: 10.1016/S12783218(02)00185-3

33. Walsh TN, Noonan N, Hollywood D, Kelly A, Keeling N, Hennessy TPJ. A comparison of multimodal therapy and surgery for esophageal adenocarcinoma. New Engl J Med 1996;335:462-7. doi: 10.1056/ NEJM199608153350702

34. Bosset JF, Gignoux M, Triboulet JP, et al. Chemoradiotherapy followed by surgery compared with surgery alone in squamous cell cancer of the esophagus. New Engl J Med 1997;337:161-7. doi: 10.1056/ NEJM199707173370304

35. Burmeister BH, Smithers BM, Fitzgerald L, Simes R, Devitt S, Ackland S, et al. Surgery alone versus chemoradiotherapy followed by surgery for resectable cancer of the oesophagus: a randomised controlled phase III trial. Lancet Oncol 2005;6:659-68. doi: http:// dx.doi.org/10.1016/S1470-2045(05)70288-6

36. Tepper JE, Krasna MJ, Niedzwieki D, Hollis D, Reed CE, Goldberg R, et al. Phase III trial of trimodality therapy with cisplatin, fluorouracil, radiotherapy, and surgery compared with surgery alone for esophageal cancer: CALGB 9781. J Clin Oncol 2008;26:1086-92. doi: 10.1200/JCO.2007.12.9593

37. Van Hagen P, Hulshof MCCM, Van Lanschot JJB, et al. Preoperative chemoradiotherapy for esophageal or junctional cancer. N Engl J Med 2012;366:2074-84.

doi: 10.1056/NEJMoa1112088

38. Bedenne L, Michel P, Bouche O, Milan C, Mariette C, Conroy $\mathrm{T}$, et al. Chemoradiation followed by surgery compared with chemoradiation alone in squamous cell cancer of the esophagus: FFCD 9102. J Clin Oncol 2007;25:1160-8. doi: 10.1200/JCO.2005.04.7118

39. Bonnetain F, Bouche O, Michel P, Mariette C, Conroy $\mathrm{T}$, Pezet $\mathrm{D}$, et al. A comparative longitudinal quality of life study using the spitzer quality of life index in a randomized multicenter phase III trial (FFCD 9102): chemoradiation followed by surgery compared with chemoradiation alone in locally advanced squamous resectable thoracic esophageal cancer. Ann Oncol 2006;17:827-34. doi: 10.1093/annonc/mdl033

40. Crehange G, Maingon P, Peignaux K, N'guyen TD, Mirabel X, Marchal C, et al. Phase III trial of protracted compared with split-course chemoradiation for esophageal cancer: Federation Francophone de Cancerologie Digestive 9102. J Clin Oncol 2007;25:4895-901. doi: 10.1200/JCO.2007.12.3471

41. Stahl M, Stuschke M, Lehmann N, Meyer HJ, Walz MK, Seeber S, et al. Chemoradiation with and without surgery in patients with locally advanced squamous cell carcinoma of the esophagus. J Clin Oncol 2005;23:23107. doi: 10.1200/JCO.2005.00.034

42. Berger AC, Farma J, Scott WJ, et al. Complete response to neoadjuvant chemoradiotherapy in esophageal carcinoma is associated with significantly improved survival. J Clin Oncol 2005;23:4330-7. doi: 10.1200/ JCO.2005.05.017

43. Rohatgi P, Swisher S, Correa AM, et al. Characterization of pathologic complete response after preoperative chemoradiotherapy in carcinoma of the esophagus and outcome after pathologic response. Cancer 2005;104:2365-72. doi: 10.1002/cncr.21439

44. Swisher SG, Hofsetter W, Wu TT, et al. Proposed revision of the esophageal cancer staging system to accommodate pathologic response (pP) following preoperative chemoradiation (CRT). Ann Surg 2005;241:810-20. doi: 10.1097/01.sla.0000161983.82345.85

45. Swisher SG, Winter KA, Komaki RU, et al. A phase II study of a paclitaxel-based chemoradiation regimen with selective surgical salvage for resectable locoregionally 
advanced esophageal cancer: initial reporting of RTOG 0246. Int J Radiat Oncol Biol Phys 2012;82:1967-72. doi:10.1016/j.ijrobp.2011.01.043

46. Gaca JG, Petersen RP, Peterson BL, Harpole DH, D'Amico TA, Pappas TN, et al. Pathologic nodal status predicts disease-free survival after neoadjuvant chemoradiation for gastroesophageal junction carcinoma. Ann Surg Oncol 2006;13:340-6. doi: 10.1245/ASO.2006.02.023

47. Bates BA, Detterbeck FC, Bernard SA, Qaqish BF, Tepper JE. Concurrent radiation therapy and chemotherapy followed by esophagectomy for localized esophageal carcinoma. J Clin Oncol 1996;14:156-63. doi: 10.1016/0360-3016(94)90828-1

48. Jones DR, Parker LA, Detterbeck FC, Egan TM. Inadequacy of computed tomography in assessing patients with esophageal carcinoma after induction chemoradiotherapy. Cancer 1999;85:1026-32. doi: 10.1002/(SICI)1097-0142(19990301)85:5<1026::AIDCNCR3>3.0.CO;2-N

49. Lightdale CJ, Kulkarni KG. Role of Endoscopic Ultrasonography in the Staging and Follow-Up of Esophageal Cancer. J Clin Oncol 2005;23:4483-9. doi: 10.1200/JCO.2005.20.644

50. Sarkaria IS, Rizk NP, Bains MS, et al. Post-treatment endoscopic biopsy is a poor-predictor of pathologic response in patients undergoing chemoradiation therapy for esophageal cancer. Ann Surg 2009;249:764-7. doi: 10.1097/SLA.0b013e3181a38e9e

51. Wieder HA, Ott K, Lordick F, et al. Prediction of tumor response by FDG-PET: comparison of the accuracy of single and sequential studies in patients with adenocarcinomas of the esophagogastric junction. Eur J Nucl Med Mol Imaging 2007;34:1925-32. doi: 10.1007/s00259-007-0521-3

52. Ott K, Weber WA, Lordick F, Becker K, Busch R, Herrmann K, et al. Metabolic imaging predicts response, survival, and recurrence in adenocarcinomas of the esophagogastric junction. J Clin Oncol 2006;24:46928. doi: 10.1200/JCO.2006.06.7801

53. Vallbohmer D, Holscher AH, Dietlein M, Bollschweiler E, Baldus SE, Monig SP, et al. [18F] fluorodeoxyglucosepositron emission tomography for the assessment of histologic response and prognosis after completion of neoadjuvant chemoradiation in esophageal cancer. Ann Surg 2009;250:888-94.

54. Flamen P, Van Cutsem E, Lerut $\mathrm{T}$, et al. Positron emission tomography for assessment of the response to induction radiochemotherapy in locally advanced oesophageal cancer. Ann Oncol 2002;13:361-8. doi: 10.1093/annonc/mdf081

55. Klayton T, Li T, Yu JQ, Keller L, Cheng J, Cohen SJ, et al. The role of qualitative and quantitative analysis of F18-FDG positron emission tomography in predicting pathologic response following chemoradiotherapy in patients with esophageal carcinoma. J Gastrointest Cancer 2012;43:612-8. doi: 10.1007/s12029-012-9412-3

56. Swisher SG, Erasmus J, Maish M, et al. 2-Fluoro2-deoxy-D-glucose positron emission tomography imaging is predictive of pathologic response and survival after preoperative chemoradiation in patients with esophageal carcinoma. Cancer $2004 ; 101: 1776-$ 85. doi: $10.1002 /$ cncr. 20585

57. Monjazeb AM, Riedlinger G, Aklilu M, et al. Outcomes of patients with esophageal cancer staged with $[18 \mathrm{~F}]$ fluorodeoxyglucose positron emission tomography (FDG-PET): can postradiochemotherapy FDGPED predict the utility of resection? J Clin Oncol 2010;28:4714-21. doi: 10.1200/JCO.2010.30.7702

58. Eng CW, Fuqua JL 3rd, Grewal R, et al. Evaluation of response to induction chemotherapy in esophageal cancer: is barium esophagography or PET-CT useful? Clin Imaging 2013;37:468-74. doi: 10.1016/j.clinimag. 2012.08.003

59. Erasmus JJ, Munden RF, Truong MT, et al. Preoperative chemo-radiation-induced ulceration in patients with esophageal cancer: a confounding factor in tumor response assessment in integrated computed tomographic-positron emission tomographic imaging. J Thorac Oncol 2006;1:478-86. doi: 10.1097/01243894200606000-00016

60. Morita M, Kuwano H, Araki K, Egashira A, Kawaguchi $\mathrm{H}$, Saeki H, et al. Prognostic significance of lymphocytic infiltration following preoperative chemoradiotherapy and hyperthermia for esophageal cancer. Int $\mathrm{J}$ Radiat Oncol Biol Phys 2001;49:1259-66. doi:10.1016/S03603016(00)01465-6

61. Alexander BM, Wang XZ, Niemierko A, et al. DNA repair biomarkers predict response to neoadjuvant chemoradiotherapy in esophageal cancer. Int J Radiat Oncol Biol Phys 2012;83:164-71. doi: 10.1016/j. ijrobp.2011.05.033

62. Kuwahara A, Yamamori M, Fujita M, et al. TNFRSF1B A1466G genotype is predictive of clinical efficacy after treatment with a definitive 5-fluorouracil/cisplatin-based chemoradiotherapy in Japanese patients with esophageal 
squamous cell carcinoma. J Exp Clin Cancer Res 2010;29:100. doi:10.1186/1756-9966-29-100

63. Yi Y, Li B, Sun H, et al. Predictors of sensitivity to chemoradiotherapy of esophageal squamous cell carcinoma. Tumour Biol 2010 ;31:333-40. doi: 10.1007/ s13277-010-0041-9

64. Gotoh M, Takiuchi H, Kawabe S, et al. Epidermal growth factor receptor is a possible predictor of sensitivity to chemoradiotherapy in the primary lesion of esophageal squamous cell carcinoma. Jpn J Clin Oncol 2007;37:652-7. doi: 10.1093/jjco/hym089

65. Luthra R, Luthra MG, Izzo J, et al. Biomarkers of response to preoperative chemoradiation in esophageal cancers. Semin Oncol 2006;33(6 Suppl 11):S2-5. doi:10.1053/j.seminoncol.2006.10.004

66. Izzo JG, Correa AM, Wu T-T, et al. Pretherapy nuclear factor-kappaB status, chemoradiation resistance, and metastatic progression in esophageal carcinoma. Mol Cancer Ther 2006;5:2844-50. doi: 10.1158/1535-7163. MCT-06-0351

67. Wu X, Gu J, Wu T-T, et al. Genetic variations in radiation and chemotherapy drug action pathways predict clinical outcomes in esophageal cancer. J Clin Oncol 2006;24:3789-98. doi: 10.1200/JCO.2005.03.6640

68. Okumura H, Natsugoe S, Matsumoto M, et al. The predictive value of p53, p53R2, and p21 for the effect of chemoradiation therapy on oesophageal squamous cell carcinoma. Br J Cancer 2005;92:284-9. doi: 10.1038/ sj.bjc. 6602322

69. Sohda M, Ishikawa H, Masuda N, et al. Pretreatment evaluation of combined HIF-1alpha, p53 and p21 expression is a useful and sensitive indicator of response to radiation and chemotherapy in esophageal cancer. Int J Cancer 2004 20;110:838-44. doi: 10.1002/ijc.20215

70. Harpole DH Jr, Moore MB, Herndon JE et al. The prognostic value of molecular marker analysis in patients treated with trimodality therapy for esophageal cancer. Clin Cancer Res 2001;7:562-9.

71. Skinner HD, Xu E, Lee JH, et al. A validated miRNA expression profile for response to neoadjuvant therapy in esophageal cancer. J Clin Oncol [Internet]. 2013 [cited 2013 26];31(suppl; abstr 4078). Available from: http:// meetinglibrary.asco.org/content/82991 doi: 10.1002/ cncr.28911 